Centers for Disease Control and Prevention (USA) and the Laboratory Centre for Disease Control (Canada). Clin Infect Dis 2001; 33: 492-503.

3 Kern DG, Neill MA, Schachter J. A seroepidemiologic study of Chlamydia pneumoniae in Rhode Island. Evidence of serologic cross-reactivity. Chest 1993; 104: 208-213.

4 Johnston SL, Blasi F, Farrell DJ, Nieman RB. Chlamydia pneumoniae infection in patients with acute exacerbations of asthma: the TELICAST study. Am J Respir Crit Care Med 2004; 169: A586.

5 Hahn DL, Dodge R, Golubjatnikov R. Association of Chlamydia pneumoniae (strain TWAR) infection with wheezing, asthmatic bronchitis and adult-onset asthma. JAMA 1991; 266: 225-230.
6 Wark PA, Johnston SL, Simpson JL, Hensley MJ, Gibson PG. Chlamydia pneumoniae immunoglobulin A reactivation and airway inflammation in acute asthma. Eur Respir J 2002; 20: 834-840.

7 Corne JM, Marshall C, Smith S, et al. Frequency, severity, and duration of rhinovirus infections in asthmatic and non-asthmatic individuals: a longitudinal cohort study. Lancet 2002; 359: 831-834.

8 Aldous MB, Grayston JT, Wang S-P, Foy HM. Seroepidemiology of Chlamydia pneumoniae TWAR infection in Seattle families, 1966-1979. J Infect Dis 1992; 166: 646-649.

\title{
Nasal potentials at high altitude
}

\section{To the Editors:}

In their recent publication in the European Respiratory Journal, SARTORI et al. [1] explain the difference between their results and previous studies by arguing that in other studies "no particular care was taken to locate the electrode in the inferior turbinate", without contacting the investigators who performed the measurements that they criticise. This argument is not acceptable for us. We can assure them that we paid very careful attention to the placement of the nasal electrode as we are well aware that potentials vary considerably in magnitude in different regions of the nose $[2,3]$. The fact that the magnitude of measured potentials is comparable among all studies at high altitude rules out a significant effect of the site of recording and disproves the argument by SARTORI et al. [1].

We would like to make further observations on the discrepant results which are summarised in table 1 . In a study by MAIRBÄURL et al. [5], performed in 1999 in freezing temperatures and strong winds, subjects reported dryness of the nasal epithelium. This was not a problem in a second study performed in 2003 [6] when weather conditions were warm and nasal dryness was prevented with aerosolised isotonic saline. This manoeuvre entirely prevented the hyperpolarisation of total nasal potential difference. MASON et al. [4] and
SARTORI et al. [1] did not observe a problem with nasal dryness, although the subjects in MASON et al. [4] bathed their nostrils with isotonic saline twice daily. These variations indicate the problems and difficulty of interpretation of nasal potential difference measurements. MAIRBÄURL et al. [5] found no statistically significant change in the amiloride-sensitive change in the nasal potential difference (NP $\Delta$ amil) in highaltitude pulmonary oedema (HAPE)-susceptible subjects; only a nonsignificant trend was reported, whereas, in another study by MAIRBÄURL et al. [6], significantly decreased NP $\Delta$ amil in HAPE was seen, again pointing to possible effects of nasal dryness. This argument is strengthened by the increase seen in the chloride-sensitive change in the nasal potential difference $(\mathrm{NP} \Delta \mathrm{Cl})$ reported by both MAIRBÄURL et al. [5] and MASON et al. [4]. Increased $\mathrm{NP} \Delta \mathrm{Cl}$ is compatible with increased nasal secretion. This possibility was not addressed in the study by SARTORI et al. [1].

In summary, these results indicate that the potential across the nasal epithelium might very well be affected by climatic conditions [7] to which the nose is exposed but to which the alveolar epithelium is not [1,4]. Due to this, particular caution must be exercised when extrapolating data obtained at the nasal epithelium to make claims about changes occurring at the level of the alveolar epithelium.

TABLE 1 Studies reporting the change in nasal potential difference upon ascent to high altitude

\begin{tabular}{|c|c|c|c|c|c|c|}
\hline Change upon ascent to high altitude & Co-NPtot & HAPE-NPtot & Co-NP $\Delta$ amil & HAPE-NP $\triangle$ amil & Co-NPamilis & HAPE-NPamil-is \\
\hline SARTORI et al. [1] & NS & $\#$ & NS & NS & \# & \# \\
\hline MASON et al. [4] & $\cdot$ & & NS & NS & $\cdot$ & \\
\hline MAIRBÄURL et al. [5] & $\bullet$ & • & $\#$ & NS & $\cdot$ & • \\
\hline MAIRBÄURL et al. [6] & & \# & & $\#$ & & \# \\
\hline
\end{tabular}

Co: controls; NPtot: total nasal potential difference; HAPE: high-altitude pulmonary oedema; NPAamil: amiloride-sensitive change in the nasal potential difference; NPAamil-is: amiloride-insensitive nasal potential difference; \#: decreased potential difference, more positive values; " : increased potential difference, more negative values; NS: no significant change. Symbols are shown only when changes were reported to be statistically significant. 
H. Mairbäurl*, N. Mason ${ }^{\#}$ and P. Bärtsch*

*Medical Clinic VII, Sports Medicine, University of Heidelberg, Germany. "Dept of Critical Care Medicine, University Hospital Wales, Cardiff, UK.

\section{REFERENCES}

1 Sartori C, Duplain H, Lepori M, et al. High altitude impairs nasal transepithelial sodium transport in HAPE-prone subjects. Eur Respir J 2004; 23: 916-920.

2 Knowles MR, Buntin WH, Bromberg PA, Gatzy JT, Boucher RC. Measurements of transepithelial electric potential differences in the trachea and bronchi of human subjects in vivo. Am Rev Respir Dis 1982; 126: 108-112.

3 Knowles MR, Carson JL, Collier JT, Gatzy JT, Boucher RC. Measurements of nasal transepithelial electric potential differences in normal human subjects in vivo. Am Rev Respir Dis 1981; 124: 484-490.

4 Mason NP, Petersen M, Melot C, et al. Serial changes in nasal potential difference and lung electrical impedance tomography at high altitude. J Appl Physiol 2003; 94: 2043-2050.

5 Mairbäurl H, Weymann J, Möhrlein A, et al. Nasal epithelium potential difference at high altitude $(4559 \mathrm{~m})$ : evidence for secretion. Am J Respir Crit Care Med 2003; 167: 862-867.

6 Mairbäurl H, Bärtsch P, Peth S, et al. Dexamethasone prevents high-altitude pulmonary oedema without effects on nasal potentials. Eur Respir J 2004; 24: Suppl. 48, 327s.

7 Canning BJ. Neurology of allergic inflammation and rhinitis. Curr Allergy Asthma Rep 2002; 2: 210-215.

DOI: $10.1183 / 09031936.04 .00118104$

\section{From the authors:}

We were pleased to learn that MAIRBÄURL et al. [1] recently confirmed our data on the effects of high altitude on nasal potential difference in high-altitude pulmonary oedema-prone subjects [2]. This raises the important problem that their previous data may represent an artefact [3]. We speculated that, among other factors, differences in the recording site used for nasal potential difference may have contributed to this artefact. MAIRBÄURL et al. [1] now speculate that nasal dryness and cold temperature, rather than improper location of the recording electrode, was the cause for this artefact, but fail to provide any direct experimental evidence for their speculation.
We have recently shown in mice that not only does a very close relationship between nasal and alveolar epithelial potential difference exist, but also, even more importantly, nasal potential difference is very closely correlated $(r=0.81)$ with alveolar fluid clearance [4]. Moreover, and of paramount importance with regards to the translation of these findings into the clinical setting, in mice, nasal potential difference very reliably predicted propensity to develop experimental pulmonary oedema and time of resolution of pulmonary oedema in vivo [4]. In high-altitude pulmonary oedema-prone humans, decreased nasal potential difference indicates that alveolar fluid clearance is impaired, and, consistent with this concept, stimulation of fluid clearance with the $\beta$-adrenergic agonist salmeterol prevents pulmonary oedema during high-altitude exposure [5]. Taken together, these data indicate that, when used properly by experienced investigators, nasal potential difference does reflect alveolar fluid clearance in both animals and humans.

\section{Sartori, M. Egli and U. Scherrer}

Dept of Internal Medicine, Botnar Center for Clinical Research, Centre Hospitalier Universitaire Vaudois, Lausanne, Switzerland.

\section{REFERENCES}

1 Mairbäurl H, Bärtsch $\mathrm{P}$, Peth $\mathrm{S}$, et al. Dexamethasone prevents high altitude pulmonary oedema without effects on nasal potential. Eur Respir J 2004; 24: Suppl. 48, 327s.

2 Sartori C, Duplain H, Lepori M, et al. High altitude impairs the lung transepithelial sodium transport in HAPE-prone subjects. Eur Respir J 2004; 23: 916-920.

3 Mairbäurl H, Weymann J, Mohrlein A, et al. Nasal epithelium potential difference at high altitude $(4,559 \mathrm{~m})$ : evidence for secretion. Am J Respir Crit Care Med 2003; 167: 862-867.

4 Egli M, Duplain H, Lepori M, et al. Defective respiratory amiloride sensitive sodium transport predisposes to pulmonary oedema and delays its resolution in mice. J Physiol 2004; 560: 857-865.

5 Sartori C, Allemann Y, Duplain H, et al. Salmeterol for the prevention of high-altitude pulmonary edema. $N$ Engl J Med 2002; 346: 1631-1636. 